\title{
Rapid Simultaneous Determination of Organic Acids, Free Amino Acids, and Lactose in Cheese by Capillary Electrophoresis
}

\author{
J. M. Izco, M. Tormo, and R. Jiménez-Flores \\ Dairy Products Technology Center \\ California Polytechnic State University \\ San Luis Obispo, CA 93407
}

\begin{abstract}
A capillary electrophoresis $(\mathrm{CE})$ method for the simultaneous separation of 11 metabolically important organic acids (oxalic, formic, citric, succinic, orotic, uric, acetic, pyruvic, propionic, lactic, and butyric), 10 amino acids (Asp, Glu, Tyr, Gly, Ala, Ser, Leu, Phe, Lys, and Trp), and lactose has been optimized, validated, and tested in dairy products. Repeatability and linearity were calculated for each compound, with detection limit values as low as $0.2 \cdot 10^{-2} \mathrm{~m} M$ for citric acid and Gly. The method was applied to analyze yogurt and different varieties of commercial cheeses. This method yielded specific CE patterns for different varieties of cheese. Also, it has been shown to be sensitive enough to measure small changes in composition of some of those compounds in fresh cheese stored under accelerated ripening conditions for $2 \mathrm{~d}$ at $32^{\circ} \mathrm{C}$ (e.g., from $1728.3 \pm 45.0$ to $1166.7 \pm 4.5 \mathrm{mg} / 100 \mathrm{~g}$ of $\mathrm{DM}$ in the case of lactose, or from $23.5 \pm 0.6$ to $76.8 \pm 16.7 \mathrm{mg} / 100 \mathrm{~g}$ of $\mathrm{DM}$ in the case of acetic acid).
\end{abstract}

(Key words: organic acids and amino acids, lactose, cheese, capillary electrophoresis)

Abbreviation key: BGE = background electrolyte, $\mathbf{C E}$ = capillary electrophoresis, $\mathbf{C T A B}=$ hexadecyltrimethylammonium bromide, EOF = electroosmotic flow, $\boldsymbol{f}=$ response factor, i.d. $=$ internal diameter, $\mathbf{I S}=$ internal standard, LAB = lactic acid bacteria, NSLAB = nonstarter LAB, PDC = 2,6-pyridinedicarboxylic acid, p.s.i. $=$ pound square inch.

\section{INTRODUCTION}

Three primary biochemical events occur during manufacturing and ripening of cheese: glycolysis, proteolysis, and lipolysis. These changes together with numer-

Received March 6, 2002.

Accepted March 21, 2002.

Corresponding author: R. Jiménez-Flores; e-mail: rjimenez@ calpoly.edu. ous concomitant secondary transformations taking place during ripening determine the finer aspects of the flavor and texture of cheese. During the manufacturing phase, lactose is converted to lactic acid by the starter bacteria. In the case of Cheddar cheese, most of the lactic acid is produced in the vat before salting and molding, whereas for most other varieties, acidification occurs after the curd has been placed in molds (Fox, 1993).

Organic acids may appear in cheese as a result of hydrolysis of milk fat during lipolysis (FFA such as acetic or butyric), normal bovine biochemical metabolism (citric, orotic, and uric), or bacterial growth (lactic, acetic, pyruvic, propionic, and formic). These are the major products of carbohydrate catabolism of lactic acid bacteria (LAB). The resulting acidity prevents the development of spoilage and pathogenic microorganisms, improving the hygienic quality of cheese. However, the ability of LAB to inhibit undesirable bacteria depends not only on the reduction of $\mathrm{pH}$, but also on the sort of organic acids they produce (Izco et al., 2002). Quantitative determination of organic acids is important for monitoring bacterial growth and activity and for nutritional reasons and because organic acids contribute to the flavor and aroma characteristics of most cheeses (Fox, 1993; González de Llano et al., 1996).

Proteolysis is the most complex of the three events during ripening. It is also the major contributor to the changes taking place in the cheese matrix and occurs in most pressed-curd cheeses (Irigoyen at al., 2001). Casein breakdown liberates amino acids and peptides that directly contribute to cheese flavor. Because nonstarter LAB (NSLAB) possess a wide range of hydrolytic enzymes, they affect proteolysis and lipolysis during ripening and, therefore, the flavor of the cheese (Lane and Fox, 1996). Also, NSLAB adjuncts have been shown to accelerate the production of amino acids (Lynch et al., 1996). Furthermore, some amino acids (e.g., Glu, Leu, and Lys) have been linearly correlated with ripening time in Idiazábal and Ossau-Iraty cheese and are very helpful indicators of the degree of ripening (Izco et al., 2000). 
These types of compounds have been analyzed by a variety of different analytical techniques. Until a few years ago, organic acids were commonly analyzed by chromatographic techniques. Most methods developed to analyze organic acids in dairy products are based on HPLC (Fernández-García and McGregor, 1994; Mullin and Emmons, 1997). Amino acids are analyzed by HPLC methods with pre- or postcolumns derivatization and ultraviolet or fluorescence detection (Izco et al., 2000). On the other hand, the analysis of carbohydrates normally is performed by HPLC with a refractive index detector, whereas the analysis of lactose in milk may be carried out by polarimetric, gravimetric or enzymatic methods (AOAC, 1995). Because analytical instrumentation, separation columns, mobile phases, and detectors are different, at least three different systems and methods are necessary for a complete analysis. Therefore, an easy, efficient, and rapid simultaneous analysis method for these compounds would be a great benefit.

Capillary electrophoresis (CE) has emerged as a powerful separation technique that can provide high resolution and efficiency, offering great potential for rapid detection and quantification. Recently we developed a $\mathrm{CE}$ method to analyze 11 metabolically important organic acids (Izco et al., 2002). The fact that the amino acids and lactose can be charged (using $\mathrm{pH}$ values higher than their respective $\mathrm{pK}_{\mathrm{a}}$ values would have a net negative charge) suggests that they could be separated by $\mathrm{CE}$. By applying a negative voltage, the anions migrate toward the detector situated at the anode end of the capillary. Addition of modifiers, such as hexadecyltrimethylammonium bromide (CTAB), reverse the direction of the electroosmotic flow (EOF) inside the capillary and promote the comigration of the analytes with the EOF, thus speeding up the analysis. Since organic acids, amino acids, and lactose have little or no UV absorbance, detection could be accomplished by indirect UV by using a background electrolyte (BGE).

The aim of this work was to establish a CE method for the simultaneous separation and quantification of organic acids, lactose, and several amino acids in cheese and in other dairy products.

\section{MATERIALS AND METHODS}

\section{Instrumentation}

All the experiments were performed with a P/ACE MDQ Capillary Electrophoresis System (Beckman Coulter, Fullerton, CA) using a photo-diode-array detector. The system was controlled by an IBM computer equipped with 32 Karat Software for data collection and analysis. All 105-cm effective length uncoated fused-silica capillaries (75 $\mu \mathrm{m}$ i.d.) used in this work were purchased from Bio-Rad Laboratories (Richmond, CA).

\section{Reagents}

Oxalic, formic, succinic, orotic, uric, pyruvic, and lactic acids, Asp, Glu, Tyr, Gly, Ala, Ser, Leu, Phe, Lys, Trp, sodium propionate, and lactose monohydrate, were obtained from Sigma (St. Louis, MO); citric, acetic, and butyric acids were purchased from Fisher Scientific (Pittsburgh, PA). Ultrapure water (18.2 $\mathrm{M} \Omega$ ) prepared by treating deionized water with a Barnstead/Thermolyne System (Dubuque, IA) was used to prepare all solutions. Individual stock solutions of each compound at $1000 \mathrm{ppm}(10,000 \mathrm{ppm}$ in case of lactose) were pre-

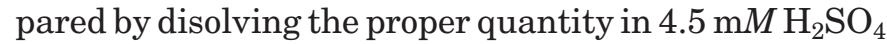
containing $15 \mathrm{ppm}$ of boric acid as an internal standard (IS), except orotic and uric acids, Asp, Glu, and Tyr, which were prepared in $0.1 \mathrm{~N} \mathrm{NaOH}$. The reagents used to prepare the running buffer were analytical or reagent grade: CTAB was purchased from Sigma and 2,6-pyridinedicarboxylic acid (PDC) was obtained from Aldrich (Milwaukee, WI).

\section{Electrophoretic Procedures and Conditions}

The conditions used to analyze the samples were based on the results obtained previously (Izco et al., 2002 ) with some modifications. The BGE was prepared daily with $20 \mathrm{~m} M$ PDC and $0.5 \mathrm{~m} M$ CTAB. The $\mathrm{pH}$ of the buffer was adjusted at 12.15 with $1 M \mathrm{NaOH}$. The separations were carried out on fused-silica capillaries with $105 \mathrm{~cm}$ of effective length $\times 75 \mu \mathrm{m}$ i.d. Before first use, a new capillary was pretreated with $0.25 M \mathrm{NaOH}$ for $10 \mathrm{~min}$, followed by water for $10 \mathrm{~min}$ and BGE for $10 \mathrm{~min}$. Before each run, the capillary was washed for 3 min with $0.25 \mathrm{M} \mathrm{NaOH}$ and preconditioned with run electrolyte for $3 \mathrm{~min}$ at 60 p.s.i. Before storing it, the capillary was rinsed for 3 min with water and dried by passing air for $1 \mathrm{~min}$ at 60 p.s.i.

The sample was injected by hydrodynamic injection for 10 s at 1 p.s.i.. The separation was performed at -25 $\mathrm{kV}$ and the capillary was thermostated at $25^{\circ} \mathrm{C}$. The wavelength for indirect UV detection was selected at $230 \mathrm{~nm}$, and the signal with negative peaks was inverted to obtain a more familiar electropherogram to integrate and process. However, orotic and uric acids absorb at $230 \mathrm{~nm}$, drastically decreasing the sensitivity for orotic acid, and uric acid appeared as a negative peak. Nevertheless, our CE System is equipped with a photo-diode array detector that allows select different wavelengths. Because these two compounds can be easily detected at $300 \mathrm{~nm}$, we set the detector at both $\lambda=$ 230 and $300 \mathrm{~nm}$. In this form, for the same analysis we 


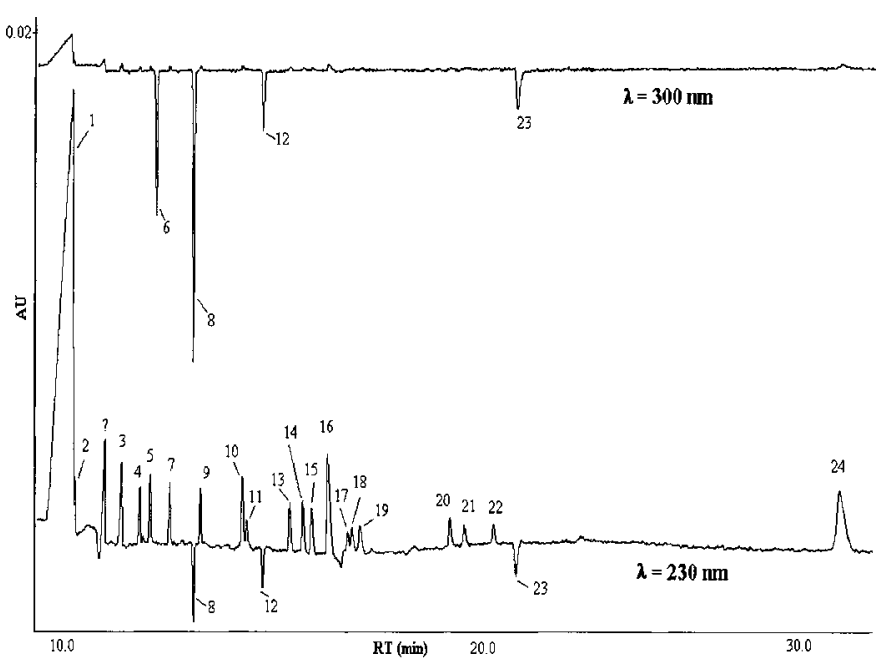

Figure 1. Electropherograms at $\lambda=230$ and $300 \mathrm{~nm}$ corresponding to the analysis of a standard mixture at $10 \mathrm{ppm}(100 \mathrm{ppm}$ in the case of lactose) in $4.5 \mathrm{mM} \mathrm{H} \mathrm{H}_{2} \mathrm{SO}_{4}$ containing boric acid as an Internal Standard (15 ppm of IS): 1: sulfuric, 2: oxalic, ?: unknown, 3: formic, 4: citric, 5: succinic, 6: orotic, 7: Asp, 8: uric, 9: Glu, 10: acetic, 11: pyruvic, 12: Tyr, 13: Gly, 14: propionic, 15: lactic, 16: IS, 17: Ala, 18: butyric, 19: Ser, 20: Leu, 21: Phe, 22: Lys, 23: Trp, 24: lactose.

obtained one electropherogram at $300 \mathrm{~nm}$ to quantify orotic and uric acids and another at $230 \mathrm{~nm}$ for the rest of compounds (Figure 1).

\section{Samples and Sample Preparation}

Pasteurized whole milk was obtained from the Dairy Products Technology Center (DPTC, San Luis Obispo, CA). All the commercial samples of cheese and plain yogurt were purchased at local stores. For the extraction of the compounds of interest $1 \mathrm{~g}(200 \mu \mathrm{l}$ in the case of milk) of sample was weighed and, depending on the commercial sample, a volume of sample buffer consisting of $4.5 \mathrm{mM} \mathrm{H} \mathrm{H}_{2} \mathrm{SO}_{4}$ containing $15 \mathrm{ppm}$ of boric acid as IS was added $(1 \mathrm{ml}$ in the case of milk, $12 \mathrm{ml}$ in the case of yogurt, $20 \mathrm{ml}$ in the case of fresh cheese, $50 \mathrm{ml}$ in the case of Cheddar cheese, and $100 \mathrm{ml}$ for Parmesan, Roncal, and Blue cheese). The mixture was homogenized for 1 min using an Ultra-Turrax blender and, after that, stirred for $15 \mathrm{~min}$. One milliliter of the sample was centrifuged a 14,000 rpm for $1 \mathrm{~min}$, and the supernatant was filtered through a $0.45-\mu \mathrm{m}$ PVDF membrane (GelmanSciences, Ann Arbor, MI).

\section{RESULTS AND DISCUSSION}

\section{Separation Optimization and Validation}

Recently (Izco et al., 2002), a CE method was developed in our laboratory to separate the organic acids mentioned this work. In the cited study, potassium hydrogen phthalate was used as background electrolyte together with $0.27 \mathrm{mM}$ CTAB to prepare a $\mathrm{pH} 11.2$ running buffer. However, at the optimum concentration found for phthalate $(4.4 \mathrm{mM})$, the buffer capacity of the running buffer was poor. Although $20 \mathrm{mM}$ PDC was also tested in the cited work by the authors, this background electrolyte was rejected because the baseline became noisy and wavy. Nevertheless, the CE system utilized in the present work controls with great accuracy and precision the temperature of the capillary during the analysis, noticeably improving the baseline. This has allowed the utilization of $20 \mathrm{~m} M$ PDC buffer to test several parameters (run voltage, run temperature, concentration, and $\mathrm{pH}$ of the running buffer) until the optimal conditions were determined as indicated in Materials and Methods section. Taking into account the $\mathrm{pK}_{\mathrm{a}}$ values of the analytes tested, at the $\mathrm{pH}$ selected for the running buffer ( $\mathrm{pH}$ 12.15), we ensured that all the compounds were ionized, including the amino acids and the lactose. In this form, all the compounds tested were totally separated in less than 35 min (Figure 1). An unknown peak appears in the electropherogram due to the running buffer. This peak (sometimes detected as a jump of the baseline, see Figure 3, below, between peaks 2 and 3) appears only when high $\mathrm{pH}$ values running buffers are used, due to the high quantity of $\mathrm{NaOH}$ added to adjust the $\mathrm{pH}$ of the electrolyte. We have previously detected this anomaly (Izco et al., 2002). Butyric acid and Ala were not totally resolved in commercial samples (Figure 2), and it seems that Ala comigrated with an unknown peak detected in the milk after the IS (Figure 3). Also, other important amino acids such as Pro, Gln, Asn, Val, Met, or His were tested. However, these compounds appeared after the peak corresponding to Ser, and some of them comigrated with a negative unknown peak that appears in dairy samples, making their quantification impossible (see Figure 2). Also, the resolution for some of these amino acids was poorer; therefore, we decided to validate the method for the 10 amino acids selected, which are perfectly separated and identified. Some of the amino acids selected are present in different varieties of cheese, e.g., Glu, Leu, Phe, and Lys have been shown to be major in Ossau Iraty cheese (Izco et al., 2000) with a clear relationship between their concentration and the ripening time.

Tables 1 and 2 show the results obtained in the validation of the analytical technique. The calibration curves were calculated by analyzing in duplicate 5,10 , 20,50 , and $100 \mathrm{ppm}$ of each compound, except in the case of lactose, which was calculated using $50,100,200$, $500,1000,5000$, and $10,000 \mathrm{ppm}$ in order to cover the normal concentration of lactose in milk (Table 1). Boric acid was used as an IS, and the data points from calibra- 


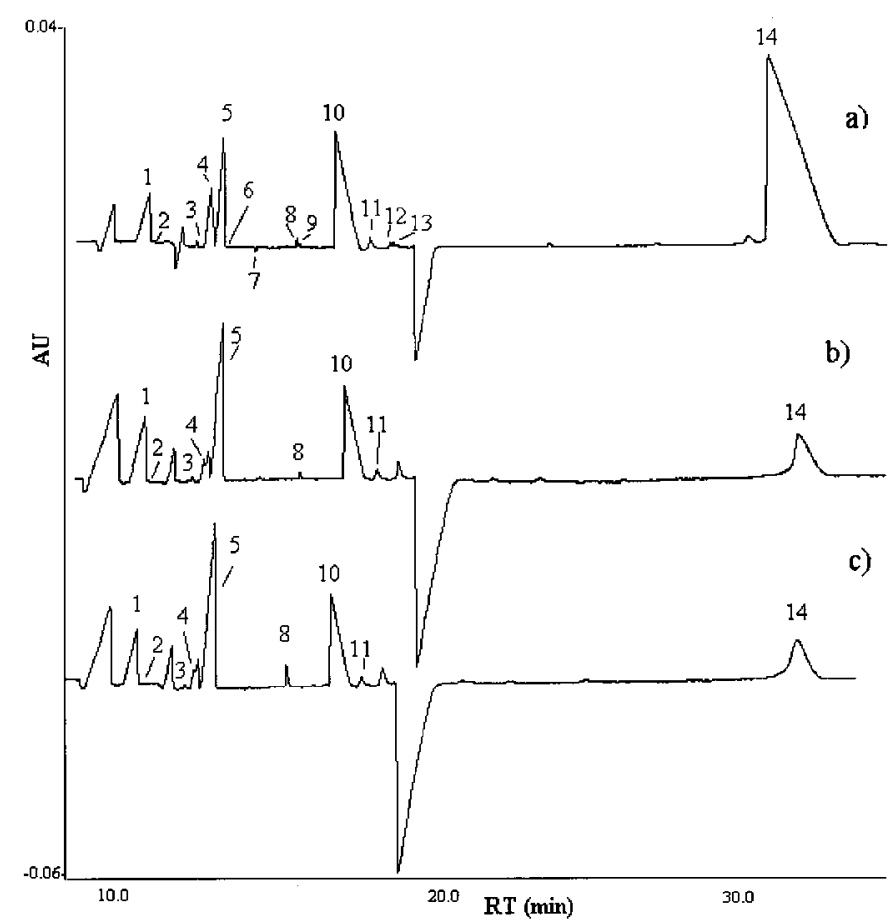

Figure 2. Electropherograms corresponding to a) plain yogurt, b) Farmer's cheese and c) Farmer's cheese stored at $32^{\circ} \mathrm{C}$ for $2 \mathrm{~d}$. 1: sulfuric, 2: oxalic, 3: formic, 4: citric, 5: phosphate, 6: succinic, 7: uric, 8: acetic, 9: pyruvic, 10: lactic, 11: IS, 12: Ala, 13: butyric, 14: lactose.

tion curves were subjected to a least square regression analysis. The slope $(a)$, intercept $(b)$, and coefficient of determination $\left(r^{2}\right)$ were calculated. Detection limits were estimated as $(3 \times a / b) \times 1 / \sqrt{n}$, where $a$ is the independent term of the curve, $b$ the slope, and $n$ is the number of replicates. The $r^{2}$ values calculated (Table 1) were better than 0.99 for all of the analytes (except for uric acid, 0.9858), showing that the linearity of the method was good and, therefore, suitable for quantification, with detection limits as low as $0.2 \cdot 10^{-2} \mathrm{~m} M$ in the case of the citric acid and Gly.

The precision of the method expressed as the coefficient of variation for five determinations of a standard mixture at $20 \mathrm{ppm}$ ( $200 \mathrm{ppm}$ in case of the lactose) was between 0.2 to $1.1 \%$ for retention time, except in the case of lactose, which showed lower repeatability of the migration time (Table 1). However, the CV values for peak areas were better than $5 \%$ for all of them (including lactose), except oxalic acid (6.4\%). That higher CV calculated for oxalic acid could be because this acid migrates close to the big peak of sulfate, which makes its quantification more difficult.

The results obtained are better than those previously obtained in the analysis of organic acids (Izco et al., 2002), where CV values around $10 \%$ for uric and citric acid, and better than $7 \%$ for the rest, were calculated. Consequently, the analytical conditions used in this work have clearly improved the CE method. Similar results have been reported by Wu et al. (1995) or Galli et al. (2000), using phosphoric acid as BGE to analyze some of these organic acids in different matrixes, and slightly better than those recorded by Chen et al. (1997), who calculated CV values of $6 \%$ using phthalate as electrolyte.

Since the recovery in the extraction of organic acids

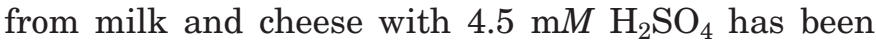
reported in the literature (Fernández-García and McGregor, 1994; González de Llano et al., 1996), our proposal was not to validate the method of extraction, but to estimate the accuracy of the analytical technique. Blue cheese was extracted, and the sample obtained was spiked with 10 and $20 \mathrm{ppm}$ of five organic acids (formic, citric, uric, acetic, and lactic) and five amino acids (Asp, Tyr, Leu, Phe, and Trp). Recovery was calculated for both cases (10 and $20 \mathrm{ppm}$ ) using the responses of the peaks and the average of the percentage recovery calculated are shown in Table 2. Since no lactose was detected in Blue cheese, cream cheese was used to calculate recovery by spiking lactose at 2500 and $1250 \mathrm{ppm}$. Recovery was close to $100 \%$ for the compounds indicated. These results are similar to the recovery calculated when extracting organic acids from milk, cheese, or yogurt with $\mathrm{H}_{2} \mathrm{SO}_{4}$ (Fernández-García and McGregor, 1994; González de Llano et al., 1996). Also, by using the high shear blender (Ultra Turrax), we shortened the extraction time from $1 \mathrm{~h}$ (González de Llano et al., 1996) to $15 \mathrm{~min}$.

\section{Application for Commercial Dairy Samples}

For all of the commercial samples, one extract was prepared from each sample, and duplicate analysis was conducted on each extract. Figure 2 shows the electropherograms corresponding to some of the commercial samples tested. The results obtained are shown in Table 3. Two electropherograms $(\lambda=230 \mathrm{~nm})$ corresponding to pasteurized whole milk and milk ripened for 30 min with starter bacteria during manufacture of Cheddar cheese are shown in Figure 3. To simplify the figure, only the electropherogram at $\lambda=300 \mathrm{~nm}$ corresponding to pasteurized milk have been included (the electropherograms were similar). Besides lactose (not shown in the figure), several organic acids (oxalic, formic, citric, orotic, uric, acetic, pyruvic, propionic, and lactic), three amino acids (Asp, Glu, and Gly), and several unknown peaks can be simultaneously detected and quantified in whole milk by this $\mathrm{CE}$ technique. As observed in Figure 3, we detected an increase of acetic and lactic acids produced by the metabolism of starter 


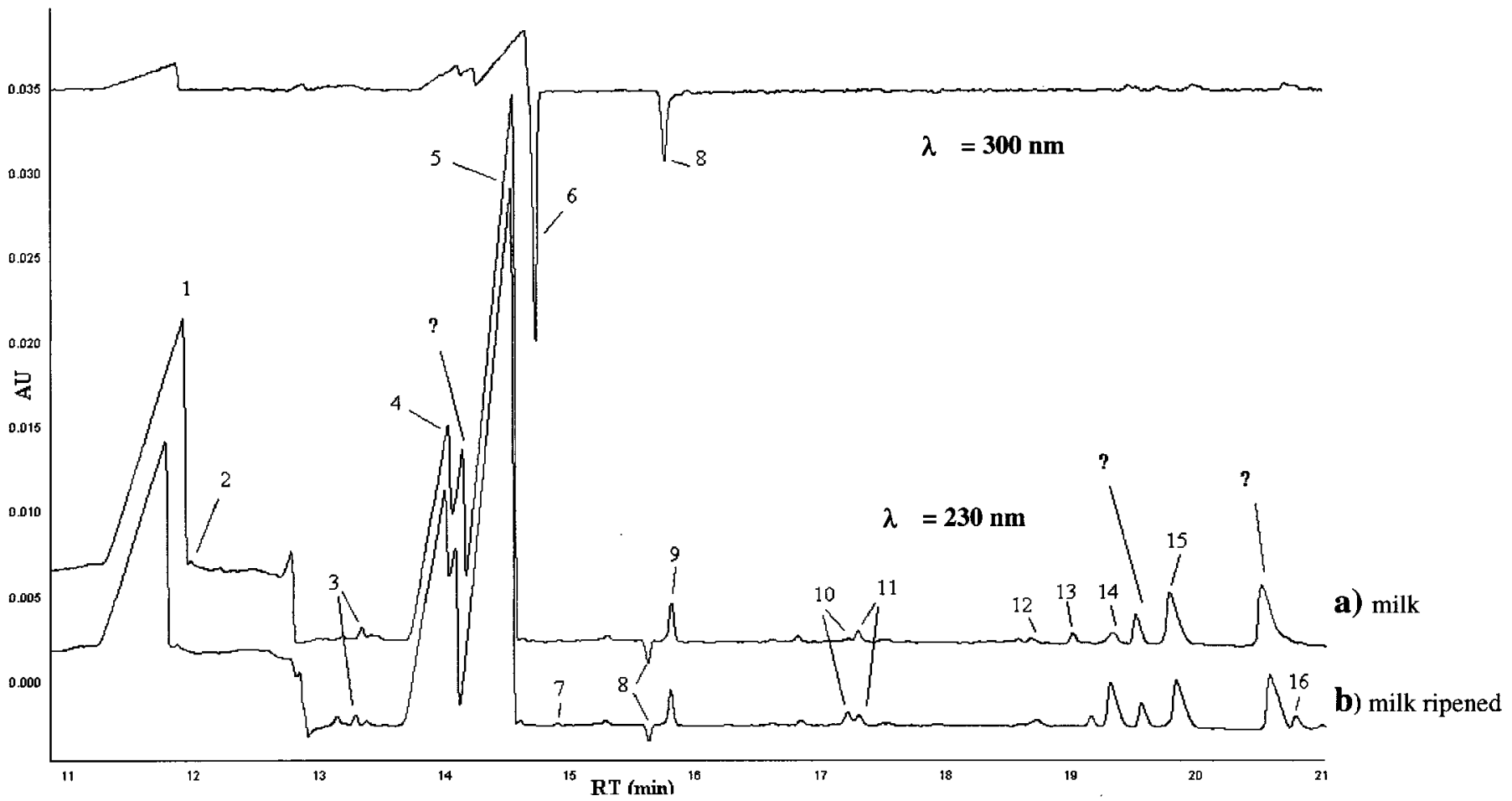

Figure 3. Electropherogram corresponding to: (a) pasteurized milk and (b) milk ripened with starter for 30 min during manufacture of Cheddar cheese. 1: sulfuric, 2: oxalic, 3: formic, 4: citric, 5: phosphoric, 6: orotic, 7: Asp, 8: uric, 9: Glu, 10: acetic, 11: pyruvic: 12: Gly, 13: propionic, 14: lactic, 15: IS, 16: butyric, ?: unknown.

Table 1. Regression equations for the calibration curves and results of the analysis of the linearity, detection limits, and precision.

\begin{tabular}{|c|c|c|c|c|c|c|}
\hline Compound & $\begin{array}{l}\text { Range } \\
(\mathrm{ppm})\end{array}$ & Regr. Equation & $\mathrm{R}^{2}$ & $\begin{array}{l}\text { Detec. } \\
\text { Limit }^{1}\end{array}$ & $\begin{array}{l}\mathrm{CV} \text { of } \\
\mathrm{RT}^{2}\end{array}$ & $\begin{array}{l}\text { CV of } \\
\text { Area }^{2}\end{array}$ \\
\hline Oxalic acid & $10-100$ & $\mathrm{Y}=2.6931 \mathrm{X}-0.0490$ & 0.9926 & $3.9 \cdot 10^{-2}$ & 1.1 & 6.4 \\
\hline Formic acid & $5-100$ & $\mathrm{Y}=3.0349 \mathrm{X}+0.0011$ & 0.9935 & $0.7 \cdot 10^{-3}$ & 1.0 & 3.5 \\
\hline Citric acid & $5-100$ & $\mathrm{Y}=7.2076 \mathrm{X}+0.0486$ & 0.9935 & $0.2 \cdot 10^{-2}$ & 1.0 & 4.9 \\
\hline Succinic acid & $5-100$ & $\mathrm{Y}=5.5146 \mathrm{X}+0.0206$ & 0.9968 & $0.8 \cdot 10^{-2}$ & 1.1 & 2.3 \\
\hline Orotic acid & $5-100$ & $Y=8.4391 X+0.0801$ & 0.9910 & $2.0 \cdot 10^{-2}$ & 1.1 & 4.6 \\
\hline Asp & $5-100$ & $\mathrm{Y}=6.2871 \mathrm{X}-0.1398$ & 0.9968 & $4.7 \cdot 10^{-2}$ & 1.0 & 3.2 \\
\hline Uric acid & $5-100$ & $\mathrm{Y}=20.868 \mathrm{X}+0.0302$ & 0.9858 & $0.3 \cdot 10^{-2}$ & 0.9 & 4.8 \\
\hline Glu & $5-100$ & $\mathrm{Y}=6.4907 \mathrm{X}-0.1274$ & 0.9974 & $4.2 \cdot 10^{-2}$ & 1.0 & 4.5 \\
\hline Acetic acid & $5-50$ & $\mathrm{Y}=3.4031 \mathrm{X}-0.0227$ & 0.9947 & $1.4 \cdot 10^{-2}$ & 1.1 & 3.7 \\
\hline Pyruvic acid & $5-50$ & $\mathrm{Y}=2.8641 \mathrm{X}-0.0272$ & 0.9989 & $2.0 \cdot 10^{-2}$ & 1.0 & 3.5 \\
\hline Tyr & $5-100$ & $\mathrm{Y}=5.9786 \mathrm{X}-0.0764$ & 0.9979 & $2.7 \cdot 10^{-2}$ & 1.0 & 3.6 \\
\hline Propinic acid & $5-100$ & $\mathrm{Y}=3.8588 \mathrm{X}-0.0059$ & 0.9972 & $0.3 \cdot 10^{-2}$ & 0.2 & 3.5 \\
\hline Gly & $5-100$ & $\mathrm{Y}=2.8296 \mathrm{X}-0.0032$ & 0.9942 & $0.2 \cdot 10^{-2}$ & 1.1 & 5.0 \\
\hline Lactic acid & $5-100$ & $\mathrm{Y}=3.0834 \mathrm{X}-0.0131$ & 0.9993 & $1.5 \cdot 10^{-2}$ & 1.1 & 4.8 \\
\hline Butyric acid & $5-100$ & $\mathrm{Y}=4.3620 \mathrm{X}-0.1162$ & 0.9915 & $5.7 \cdot 10^{-2}$ & 1.0 & 4.9 \\
\hline Ala & $5-100$ & $\mathrm{Y}=4.1434 \mathrm{X}+0.0107$ & 0.9957 & $0.5 \cdot 10^{-2}$ & $\begin{array}{l}1.0 \\
0.3\end{array}$ & 4.0 \\
\hline Ser & $5-100$ & $\mathrm{Y}=1.8270 \mathrm{X}+0.0452$ & 0.9901 & $5.3 \cdot 10^{-2}$ & 0.2 & 4.2 \\
\hline Leu & $5-100$ & $\mathrm{Y}=3.3045 \mathrm{X}+0.0973$ & 0.9945 & $6.2 \cdot 10^{-2}$ & 0.2 & 2.5 \\
\hline Phe & $5-100$ & $\mathrm{Y}=2.8356 \mathrm{X}+0.0608$ & 0.9979 & $4.5 \cdot 10^{-2}$ & 0.2 & 4.0 \\
\hline Lys & $5-100$ & $\mathrm{Y}=3.3885 \mathrm{X}-0.0545$ & 0.9963 & $4.4 \cdot 10^{-2}$ & 0.2 & 3.7 \\
\hline Trp & $5-100$ & $\mathrm{Y}=12.132 \mathrm{X}-0.1282$ & 0.9965 & $2.2 \cdot 10^{-2}$ & 0.3 & 4.0 \\
\hline Lactose & $50-10000$ & $\mathrm{Y}=9.6035 \mathrm{X}-0.8006$ & 0.9978 & $18 \cdot 10^{-2}$ & 2.7 & 3.5 \\
\hline
\end{tabular}

${ }^{1}$ Detection limit is in $\mathrm{m} M$.

${ }^{2} \mathrm{CV}$ of retention time (RT) and of corrected peak area are in $\%$. CV calculated from a standard mixture containing $20 \mathrm{ppm}(\mathrm{n}=5)$. 
Table 2. Percentage recovery of added organic acids, amino acids and lactose.

\begin{tabular}{lc}
\hline Compound & $\%$ Recovery $^{1}$ \\
\hline Formic acid & 102.3 \\
Citric acid & 101.3 \\
Asp & 98.9 \\
Uric acid & 96.0 \\
Acetic acid & 93.5 \\
Tyr & 104.0 \\
Lactic acid & 101.4 \\
Leu & 99.6 \\
Phe & 102.4 \\
Trp & 97.8 \\
Lactose & 105.6 \\
\hline
\end{tabular}

${ }^{1}$ Average of recoveries calculated after spiking an extract of blue cheese (cream cheese in the case of lactose) with a standard mixture at 10 and $20 \mathrm{ppm}$ (1250 and $2500 \mathrm{ppm}$ in the case of lactose).

culture bacteria after growing for $30 \mathrm{~min}$ by this technique (peaks 10 and 14, respectively).

The electropherogram at $\lambda=230 \mathrm{~nm}$ obtained when analyzing Blue cheese is shown in Figure 4. Twenty-one compounds were identified. A big peak corresponding to phosphate appears in the electropherogram, making the quantification of succinic acid difficult. Because the concentration of inorganic phosphate in milk is 19 to $23 \mathrm{~m} M$ (Walstra et al., 1999), it is logical to find phosphate in cheese. Several small peaks and one big negative peak have been detected, but they could not be identified. On the other hand, there are amino acids appearing between the peaks 18 and 19 that have not

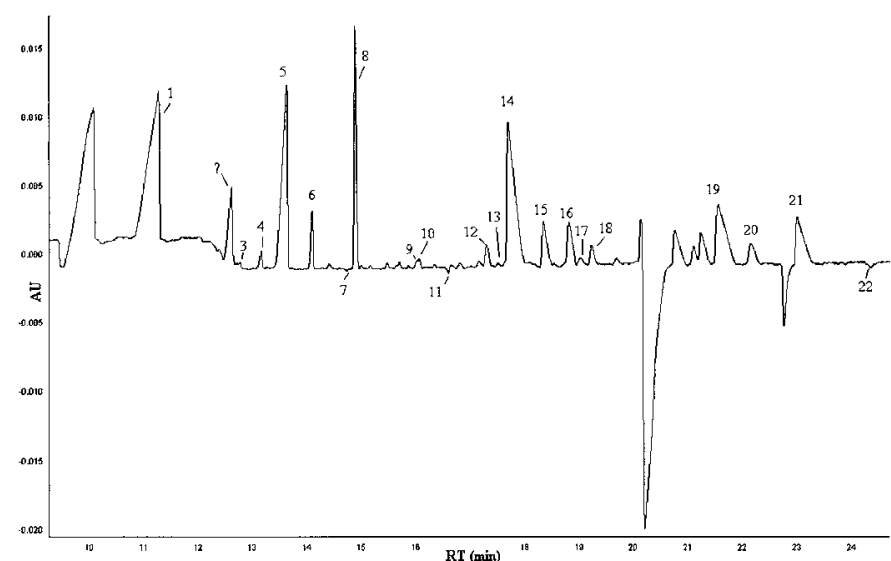

Figure 4. Electropherogram corresponding to Blue cheese. 1: sulfuric, ?: unknown, 3: formic, 4: citric, 5: phosphoric, 6: Asp, 7: uric, 8: Glu, 9: acetic, 10: pyruvic, 11: Tyr, 12: Gly, 13: propionic, 14: lactic, 15: IS, 16: Ala, 17: butyric, 18: Ser, 19: Leu, 20: Phe, 21: Lys, 22: Trp.

been labeled because some of those amino acids (Asn, Val, His, Pro, Met) coeluted as a single peak, and we could not ensure their identification.

Yogurt and fresh cheese (Farmer's cheese) showed fewer number of compounds. Asp and Glu (plus Gly in the case of yogurt) were the only FAA detected in both yogurt and fresh cheese. Because of the efficient carbohydrate (lactose in the case of milk) fermentation by LAB producing lactic acid as the major end product (Gonzalez de Llano, et al., 1996), lactic acid was the

Table 3. Concentration (mg/100 g dry matter) of the organic acids, amino acids, and lactose in some commercial samples.

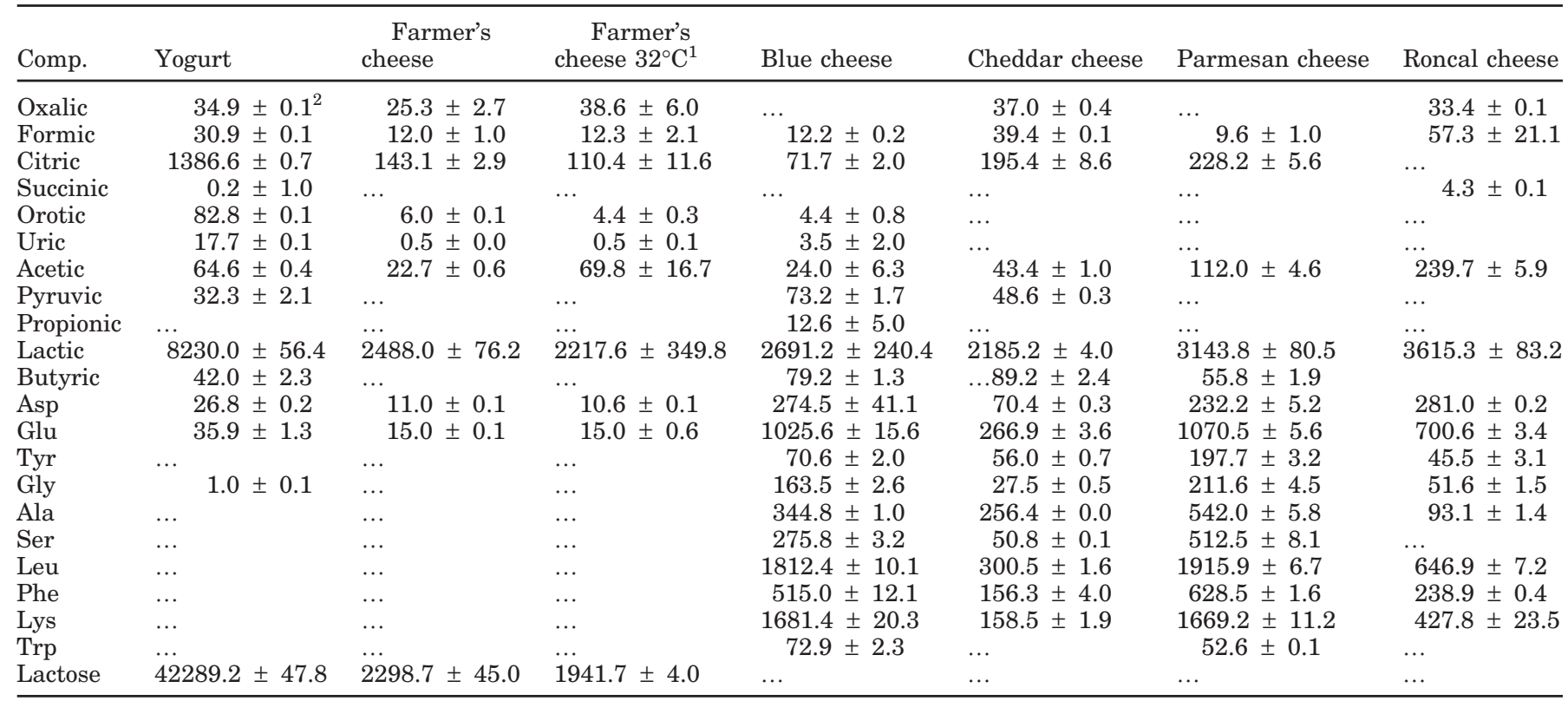

${ }^{1}$ Farmer's cheese stored at $32^{\circ} \mathrm{C}$ for $2 \mathrm{~d}$.

${ }^{2}$ Standard deviation of one extract analyzed in duplicate $(n=2)$. 
most abundant organic acid found in yogurt (8230.0 $\mathrm{mg} / 100 \mathrm{~g}$ of DM). Concentration of orotic acid found in yogurt ( $\sim 80 \mathrm{mg} / 100 \mathrm{~g} \mathrm{DM})$ was slightly higher than the values recorded by Fernández-García and McGregor (1994) when using HPLC to quantify organic acids in yogurt. The quantity of orotic acid in milk depends on the cow's origin, diet, and lactation (Gaia et al., 2000). It is an intermediate product in the synthesis of nucleotides and a growth factor for yogurt starter cultures; a decrease of up to $48 \%$ in orotic acid content during manufacturing and storage of yogurt has been reported (Arla, 1982). Concentration of citric acid remaining in yogurt (1386.6 mg/100 $\mathrm{g}$ of DM) was similar to other results $(2.3 \mathrm{mg} / \mathrm{g})$ recorded in the literature (FernándezGarcía and McGregor, 1994).

Acetic acid is another important organic acid detected in yogurt, probably formed as product of the fermentation of lactose and citric acid. As observed in Table 3, lactose has not been completely consumed by the starter bacteria in yogurt. In the same way, an important quantity remains intact in fresh cheese $(2298.7 \mathrm{mg} / 100 \mathrm{~g}$ of DM). To test the sensibility of this method, the same fresh cheese was stored at $32^{\circ} \mathrm{C}$ for $2 \mathrm{~d}$, and that period was enough to clearly detect a decrease of $15 \%$ of lactose and $24 \%$ of citric acid, whereas concentration of acetic acid increased approximately threefold. One advantage of the proposed CE method with respect to HPLC is that this method allows simultaneous analysis of lactose and those organic acids in cheese (see Figure 2). In the case of HPLC, those compounds must be analyzed separately to take advantage of the specificity and sensitivity of the detectors, and to avoid problems of coelution of some of them (Mullin and Emmons, 1997).

Lactose was not present in the aged cheese varieties analyzed (Table 3). In fact, 98\% of lactose is removed in the whey as lactose or lactate, and the complete and rapid metabolism of residual lactose remaining in the curd (0.8 to $1.5 \%)$ and its component monosaccharides is essential to produce good quality cheese (Fox, 1993).

Lactic acid is the organic acid most abundant in all cheeses tested (Table 3). Acetate may be produced by starter LAB from lactose or lactate or citrate or amino acids and must make some contribution to Cheddar cheese flavor. Nevertheless, the oxidation of lactate to acetate in cheese can be carried out by NSLAB (Fox, 1993). Because Roncal cheese is made with raw milk and the population of NSLAB is abundant, the concentration of acetic acid found in Roncal cheese $(239.7 \mathrm{mg} /$ $100 \mathrm{~g}$ of DM) may be higher than the rest. Acetic acid has been previously detected in Roncal cheese, and the importance of NSLAB for the development of the characteristic flavor of Roncal cheese has been reported also (Ortigosa et al., 2001). Perhaps, this method could be useful for the characterization of cheese made with raw milk from the same type of cheese, but manufactured with pasteurized milk. In the same form, citrate can be metabolized by starter bacteria to generate acetoin, which is reduced to butan-2,3-diol (diacetyl). In Roncal cheese, these components are reduced to butan-2-ona and butan-2-ol by microorganisms present in raw milk. All these compounds are very important flavor components of Roncal cheese (Ortigosa et al., 2001). On the other hand, due to $\mathrm{CO}_{2}$ production, rapid citrate metabolism can be responsible for the undesirable openness and floating curd in Cheedar cheese. Citric acid is not the first energy source of bacteria, but can be metabolized very rapidly by Lactococcus lactis subsp. diacetylactis or Leuconostoc spp. in Cheddar cheese. Depending on the starter used, citrate can remain constant at $2 \%(\mathrm{wt} / \mathrm{wt}$ ) up to 3 mo of ripening, and decrease to $0.1 \%$ (wt/wt) at $6 \mathrm{mo}$ (Fox, 1993). Citrate in cheese presumably reflects the concentration of colloidal citrate in milk. The concentration of citric acid in the sample of Cheddar cheese was $195.5 \mathrm{mg} / 100 \mathrm{~g}$ of DM, which is into the normal range $(0.2$ to $0.5 \%$, wt/wt) of citrate content in Cheddar cheese (Fox et al., 1993).

Proteolysis is the major contributor to the changes taking place in the cheese matrix and occurs in most pressed-curd cheeses. The main proteolytic agents are: the natural proteases of the milk, milk-clotting enzymes retained in the curd, and proteases and peptidases from starter and nonstarter bacteria. However, FAA are released mainly by the action of microbial enzymes from the starter culture (Irigoyen et al., 2001). Soluble Tyr has been used as rapid method to monitor cheese ripening because its concentration is higher in cheeses in which $\beta$-casein is extensively hydrolyzed, e.g., Blue, Cheddar, and Parmesan (Marcos and Esteban, 1993). The concentrations of this amino acid in these cheeses were $70.6,56.0$, and $197.7 \mathrm{mg} / 100 \mathrm{~g}$ of $\mathrm{DM}$, respectively, whereas $45.5 \mathrm{mg} / 100 \mathrm{~g}$ of DM was found in Roncal cheese (See Table 3). In fact, the two fraction of $\beta$-casein are not extensively hydrolyzed during ripening of Roncal cheese (Irigoyen et al., 2000), perhaps due to higher resistance of ovine $\beta$-casein fractions to proteolysis (Izco et al., 1999).

Many of the major amino acids quantified in the cheeses tested have been also reported previously, e.g., Glu, Leu, Phe, Leu, and Lys are some of the major amino acids in Parmiagiano Reggiano cheese, a high proteolytic cheese very similar to Parmesan cheese (Battistotti and Corradini, 1993); they are also major in Idiazabal and Ossau-Iraty cheese (Izco et al., 2000). Compared to the proteolysis in other cheeses, that in mold-ripened cheeses (particularly in Blue cheeses) is higher (Gripon, 1993). Extreme proteolysis results in Blue cheese and Parmesan having higher concentration of total free amino acids (measured as the sum of the 
free amino acids individually quantified) than the rest of the cheeses.

\section{CONCLUSIONS}

A CE procedure has been optimized and found to be well suited to the simultaneous analysis of lactose, the 11 metabolically important organic acids, and the 10 amino acids mentioned. Capillary electrophoresis has been shown to achieve adequate separations, and the suitability of the technique has been verified by the analysis of linearity and precision.

The proposed method appears to be an alternative to other analytical techniques, with the additional advantages of low solvent consumption (milliliters per day vs. liters per day for HPLC), short time of analysis, no hazardous solvents, and low costs compared with others (more than 1000 analysis were run with the same capillary without lost of resolution; in the case of HPLC, columns must be deeply cleaned and regenerated after a few analysis). Nevertheless, the principal advantage is that the great versatility of the method allows analysis of all those compounds simultaneously, whereas to analyze them by HPLC different columns, buffers, and chromatographic systems are necessary. The procedure offers faster and simpler sample preparation for the analysis, e.g., HPLC analysis of amino acids requires precipitation of the protein and pre- or postcolumn derivatization of the previously extracted free amino acids to detect them.

It has been demonstrated that the proposed technique yields different $\mathrm{CE}$ patterns that can be used as "reference fingerprints" for cheese varieties. The lactose and organic acid content can be used to monitor the fermentation process, providing additional information about the type of fermentation, whereas the amino acids contents are reliable indices of the proteolysis and therefore, of the ripening of cheese.

\section{ACKNOWLEDGMENTS}

The authors are very grateful to the Secretaría de Estado de Educación, Universidades, Investigación y Desarrollo of the Ministry of Education and Culture of Spain, to California Dairy Research Foundation, and to the California Agricultural Research Initiative for the funding provided for this study.

\section{REFERENCES}

AOAC International. 1995. Official Methods of Aalysis. P. Cunnif, ed. AOAC International, Gaithersburg, MD.

Arla, L. A. 1982. Effect of fermentation on B vitamin content of milk in Sweeden. J. Dairy Sci. 65:353.
Battistotti, B., and C. Corradini. 1993. Italian Cheese. Pages 221244 in Cheese: Chemistry, Physics and Microbiology. Vol. 2. Major Cheese Groups. P. F. Fox, ed. Chapman \& Hall, London.

Chen, J., B. P. Preston, and M. J. Zimmerman. 1997. Analysis of organic acids in industrial samples. Comparison of capillary electrophoresis and ion chromatography. J. Chromatogr. A 781:205-213.

Fernández-García, E., and J. U. McGregor. 1994. Determination of organic acids during the fermentation and cold storage of yogurt. J. Dairy Sci. 77:2934-2939.

Fox, P. F., J. Law, P. L. H. McSweeney, and J. Wallace. 1993. Biochemistry of cheese ripening. Pages 389-438 in Cheese: Chemistry, Physics and Microbiology. Vol. 1. General Aspects. P. F. Fox, ed. Chapman \& Hall, London.

Gaia, A., M. L. Antonelli, A. Biondi, and G. Vinci. 2000. Orotic acid: a milk constituent, Enzymatic determination by means of a new microcalorimetric method. Talanta 52:947-952.

Galli V., N. Olmo, and C. Barbas. 2000. Development and validation of a capillary electrophoresis method for the measurement of short-chain organic acids in natural rubber latex. J. Chromatogr. A 894:135-144.

González de Llano, D., A. Rodríguez, and P. Cuesta. 1996. Effect of lactic starter cultures on the organic acid composition of milk and cheese during ripening-analysis by HPLC. J. Appl. Biotechnol. 80:570-576.

Gripon, J. C. 1993. Mould-Ripened Cheeses. Pages 221-244 in Cheese: Chemistry, Physics and Microbiology. Vol. 2. Major Cheese Groups. P. F. Fox, ed. Chapman \& Hall, London.

Irigoyen, A., J. M. Izco, F. C. Ibáñez, and P. Torre. 2000. Evaluation of the effect of rennet type on casein proteolysis in an ovine milk cheese by means of capillary electrophoresis. J. Chromatogr. A. 881:59-67.

Irigoyen, A., J. M. Izco, F. C. Ibáñez, and P. Torre. 2001. Influence of rennet milk-clotting activity on the proteolytic and sensory characteristics of an ovine cheese. Food Chem. 72:137-144.

Izco, J. M., P. Torre, and Y. Barcina. 1999. Capillary electrophoresis: Evaluation of the effect of added enzymes on casein proteolysis during the ripening of a ewe's-milk cheese. Adv. Food Sci. 21:110-116

Izco, J. M., P. Torre, and Y. Barcina. 2000. Ripening of Ossau-Iarty cheese: Determination of free amino acids by RP-HPLC and of total free amino acids by the TNBS method. Food Control 11:7-11.

Izco, J. M., M. Tormo, and R. Jimenez-Flores. 2002. Development of a CE method to analyze organic acids in dairy products. Application to study the metabolism of heat-shocked spores. J. Agric. Food Chem. 50:1765-1773.

Lane, C. N., and P. F. Fox. 1996. Contribution of starter and adjunct lactobacilli to proteolysis in Cheddar cheese during ripening. Int. Dairy J. 6:715-728.

Lynch, C., P. McSweeney, P. F. Fox, T. Cogan, and F. Drinan. 1996. Manufacture of Cheddar cheese made with or without adjunct lactobacilli under controlled microbiological conditions. Int. Dairy J. 6:851-867.

Marcos, A., and M. A. Esteban. 1993. Iberian Cheeses. Pages 173220 in Cheese: Chemistry, Physics and Microbiology. Vol. 2. Major Cheese Groups. P. F. Fox, ed. Chapman \& Hall, London.

Mullin, W. J., and D. B. Emmons. 1997. Determination of organic acids and sugars in cheese, milk and whey by high performance liquid chromatography. Food Res. Int. 30:147-151.

Ortigosa, M., P. Torre, and J. M. Izco. 2001. Effect of pasteurization of ewe's milk and use of a native starter culture on the volatile components and sensory characteristics of Roncal cheese. J. Dairy Sci. 84:1320-1330.

Walstra, P., T. J. Geurts, A. Noomen, A. Jellema, and M. A. J. S. van Boekel. 1999. Dairy Technology: Principles of Milk Properties and Processes. Marcel Dekker Inc., New York.

Wu, C. H., Y. S. Lo, Y. -H. Lee, and T. - I. Lin. 1995. Capillary electrophoresis determination of organic acids with indirect detection. J. Chromatogr. A. 716:291-301. 